\title{
JAK-STAT and AKT pathway-coupled genes in erythroid progenitor cells through ontogeny
}

\author{
Vladan P Cokic ${ }^{1 *}$, Bhaskar Bhattacharya ${ }^{2}$, Bojana B Beleslin-Cokic ${ }^{3}$, Constance T Noguchi ${ }^{4}$, Raj K Puri ${ }^{2}$ \\ and Alan N Schechter ${ }^{4}$
}

\begin{abstract}
Background: It has been reported that the phosphatidylinositol 3-kinase (PI3K)-AKT signaling pathway regulates erythropoietin (EPO)-induced survival, proliferation, and maturation of early erythroid progenitors. Erythroid cell proliferation and survival have also been related to activation of the JAK-STAT pathway. The goal of this study was to observe the function of EPO activation of JAK-STAT and PI3K/AKT pathways in the development of erythroid progenitors from hematopoietic $\mathrm{CD}_{3} 4^{+}$progenitor cells, as well as to distinguish early EPO target genes in human erythroid progenitors during ontogeny.
\end{abstract}

Methods: Hematopoietic CD34 ${ }^{+}$progenitor cells, isolated from fetal and adult hematopoietic tissues, were differentiated into erythroid progenitor cells. We have used microarray analysis to examine JAK-STAT and PI3K/AKT related genes, as well as broad gene expression modulation in these human erythroid progenitor cells.

Results: In microarray studies, a total of 1755 genes were expressed in fetal liver, 3844 in cord blood, 1770 in adult bone marrow, and 1325 genes in peripheral blood-derived erythroid progenitor cells. The erythroid progenitor cells shared 1011 common genes. Using the Ingenuity Pathways Analysis software, we evaluated the network pathways of genes linked to hematological system development, cellular growth and proliferation. The KITLG, EPO, GATA1, PIM1 and STAT3 genes represent the major connection points in the hematological system development linked genes. Some JAK-STAT signaling pathway-linked genes were steadily upregulated throughout ontogeny (PIM1, SOCS2, MYC, PTPN1 1), while others were downregulated (PTPN6, PIAS, SPRED2). In addition, some JAK-STAT pathway related genes are differentially expressed only in some stages of ontogeny (STATS, GRB2, CREBB). Beside the continuously upregulated (AKT1, PPP2CA, CHUK, NFKB1) and downregulated (FOXO1, PDPK1, PIK3CG) genes in the PI3K-AKT signaling pathway, we also observed intermittently regulated gene expression (NFKBIA, YWHAH).

Conclusions: This broad overview of gene expression in erythropoiesis revealed transcription factors differentially expressed in some stages of ontogenesis. Finally, our results show that EPO-mediated proliferation and survival of erythroid progenitors occurs mainly through modulation of JAK-STAT pathway associated STATS, GRB2 and PIK3 genes, as well as AKT pathway-coupled NFKBIA and YWHAH genes.

Keywords: Erythroid progenitors, Microarray, Ontogeny, JAK-STAT pathway, AKT pathway

\section{Background}

The regulation of erythropoiesis is a very complex process requiring the coordination of different signaling pathways and molecular reactions. Many transcription factors controlling globin gene expression, such as GATA binding proteins 1/2 (GATA1/2), Krüppel-like

\footnotetext{
*Correspondence: vl@imi.bg.ac.rs

'Laboratory of Experimental Hematology, Institute for Medical Research, University of Belgrade, Belgrade 11129, Serbia

Full list of author information is available at the end of the article
}

factor (KLF1), nuclear factor erythroid-derived 2 (NFE2), have been identified and characterized. The erythroidspecific transcription factor GATA1 is a direct activator of the beta $(\beta)$-globin gene [1]. GATA1 homodimerizes and interacts with other transcription factors, such as erythroid KLF1 and friend of GATA1 (FOG), further contributing to activation of delta $(\delta)$-, gamma $(\gamma)-$, and $\beta$-globin promoters [2]. KLF1 is a zinc finger transcription factor that activates the $\beta$-globin gene promoter [3]. The protein FOG is co-expressed with GATA1 during

\section{() Biomed Central}


embryonic development in erythroid cells [4]. DRED was identified as a repressor of the epsilon $(\epsilon)$-globin gene, it appears to prevent binding of KLF1 to the $\epsilon$ globin gene promoter and silences $\epsilon$-globin expression during definitive erythropoiesis [5]. Another erythroidspecific transcription factor, called Kruppel-like factor 11 (KLF11), activates also $\gamma$ - and $\epsilon$-globin genes in vitro [6]. In primitive erythropoiesis GATA2 is primarily expressed, but later in ontogeny GATA1 expression predominates [7]. Downregulation of GATA2 is important for progression of erythroid cell differentiation [8]. A nuclear protein, special AT-rich binding protein 1 (SATB1), regulates genes through targeting chromatin remodeling and increases $\epsilon$-globin and decreases $\gamma$-globin gene expression [9]. Activation of globin production by transcription factor NFE2 is stimulated by cAMP-dependent protein kinase (PKA) in erythroid cells [10].

Genome extensive profiling has been used in several studies of erythroid differentiation [11-13]. Some of these were primarily concerned about different stages of erythropoiesis to recognize potential transcription factors regulating gene expression during terminal erythropoiesis [14]. Increased apoptotic activity has been found for peripheral blood (PB)-derived hematopoietic progenitor $\mathrm{CD}_{34}{ }^{+}$cells compared to bone marrow (BM)derived $\mathrm{CD}^{+} 4^{+}$cells [15]. It has been reported that erythropoietin (EPO) and stem cell factor (SCF) mediated synergistic expansion of primary erythroid precursors activating JAK-STAT, phosphatidylinositol 3kinase (PI3K) and MAPK pathways [16]. Activation of each of the JAK-STAT, MAPK p42/44 or PI3K-AKT pathways alone is not sufficient either to stimulate cell proliferation or inhibit apoptosis of human $\mathrm{CD} 4^{+}$cells and erythroblasts. Erythroid proliferation appears more related to simultaneous activation of JAK-STAT and MAPK p42/44 whereas the effect on cell survival correlates better with activation of PI3K-AKT, JAK-STAT and MAPK p42/44 pathways. EPO and SCF inhibit apoptosis of early erythroid CD34 ${ }^{+}$burst-forming units (BFU-E) progenitors and erythroblasts [17]. In addition, the EPO activation of JAK-STAT pathway has an important role in inhibiting apoptosis of human hematopoietic cells, similarly to the PI3K-AKT axis [18].

It has been reported that feeder layers of stroma from human fetal liver (FL), cord blood (CB), and adult bone marrow $(\mathrm{BM})$ enhance $\mathrm{CD} 34^{+}$hematopoietic progenitor cell proliferation and erythropoiesis [19]. We have examined the growth and erythroid differentiation capacity of $\mathrm{CD}_{3}{ }^{+}$cells only, already committed toward hematopoiesis in fetal and adult hematopoietic cells. Using this approach, we evaluated a broad range of genes expressed in erythroid progenitors derived from hematopoietic cells through ontogeny. The broad comparison of erythropoiesis-related signaling pathways highlighted statistically significant changes in gene expression among the examined cells. Regarding its significance, we choose to focus on JAK-STAT and PI3KAKT signaling pathways during erythroid differentiation. The most prominent genes are $\mathrm{v}$-myc (myelocytomatosis viral oncogene homolog $(M Y C))$ and pim-1 oncogene (PIM1) in the JAK-STAT pathway, whereas in the PI3KAKT pathway emerge the heat shock protein $90 \mathrm{kDa}$ alpha (HSP90AA1) and protein phosphatase 2 alpha $(P P P 2 C A)$ genes. After activation of v-akt (murine thymoma viral oncogene homolog 1 (AKT1)), cell survival is promoted via nuclear factor of kappa light polypeptide gene enhancer in B-cells 1 (NFKB1) and conserved helix-loop-helix ubiquitous kinase (CHUK) according to its elevated gene expression in the PI3K-AKT pathway. Activation of JAK-STAT pathway coupled genes is observed via STATs and protein tyrosine phosphatase, non-receptor type 11 (PTPN11) gene expression linked to transcription regulation and differentiation. We describe upregulated and downregulated genes during erythroid differentiation of hematopoietic progenitor cells, with the emphasis on JAK-STAT and PI3K-AKT coupled genes, to define the mechanism of erythropoiesis.

\section{Methods}

\section{Liquid erythroid cell cultures}

To follow erythropoiesis through ontogeny, we isolate hematopoietic $\mathrm{CD} 34^{+}$progenitor cells from corresponding fetal and adult hematopoietic tissues and stimulate in vitro erythroid differentiation. Adult PB mononuclear cells are isolated from buffy coats of three healthy donors (NIH Blood bank) using Lymphocyte Separation Medium (BioWhittaker, Walkersville, MD) and CD34 ${ }^{+}$ cells are purified by positive immunomagnetic selection with MACS cell isolation system (Miltenyi Biotec, Auburn, CA). Commercial FL-derived $\mathrm{CD}^{+}{ }^{+}$cells (Cambrex Bio Science, Inc., Walkersville, MD), CB- and BM-derived CD34 ${ }^{+}$cells (AllCells LLC, Berkeley, CA) are also isolated by positive immunomagnetic selection (Miltenyi Biotec). To stimulate erythroid differentiation, the labeled CD34 ${ }^{+}$cells of all ontogenic stages are cultured in the medium that contains $30 \%$ fetal bovine serum (FBS), $2 \mathrm{mmol} / \mathrm{L}$ glutamine, $100 \mathrm{U} / \mathrm{ml}$ penicillin, $100 \mu \mathrm{g} / \mathrm{ml}$ streptomycin, $10 \%$ deionized bovine serum albumin, $10 \mathrm{mmol} / \mathrm{L}$ mercaptoethanol, $1 \mathrm{mmol} / \mathrm{L}$ dexamethasone, $33 \mu \mathrm{g} / \mathrm{ml}$ holo-transferrin, $10 \mathrm{ng} / \mathrm{ml} \mathrm{SCF}$, $1 \mathrm{ng} / \mathrm{ml} \mathrm{IL-3} \mathrm{and} 1 \mathrm{ng} / \mathrm{ml}$ GM-CSF (Sigma, St. Louis, $\mathrm{MO}$ ), and $1 \mathrm{U} / \mathrm{ml}$ human recombinant EPO (Amgen Inc, Thousand Oaks, CA) [20]. For microarray analysis, erythroid progenitors are isolated at day 6 of erythroid cell culture at $37^{\circ} \mathrm{C}$ and $5 \% \mathrm{CO}_{2}$ with balanced $95 \%$ room air. Anti-CD71 Tricolor is used for cell staining (Beckman-Coulter, Miami, FL). Cells are fixed in PBS containing $4 \%$ formaldehyde, and acquire on an LSRII flow 
cytometer (BD Biosciences, San Jose, CA). Data are analyzed with Flowjo software (Tree Star, San Carlos, CA).

\section{Isolation of total RNA}

We use the RNeasy protocol for isolation of total RNA from erythroid progenitor cells (Qiagen, Valencia, CA) according to the manufacturer's instructions. Concentration and integrity of total RNA is assessed using an 8453 UV/Visible Spectrophotometer (Hewlett-Packard GmbH, Waldbronn, Germany) and Agilent 2100 Bioanalyzer Software (Agilent Technologies, Waldbronn, Germany).

\section{Microarray studies}

In microarray studies, the numbers of total genes overexpressed in erythroid cells of $\mathrm{CB}, \mathrm{BM}$ and $\mathrm{PB}$ origin are determined from three independent samples as biological repeats. On the other hand in case of FL-derived samples, the number of total overexpressed genes is determined in independent duplicate samples. High quality oligonucleotide glass arrays are produced containing a total of 16,659 seventy-mer oligonucleotides chosen from 750 bases of the 3' end of each ORF (Operon Inc. Valencia, CA). The arrays are produced in house by spotting oligonucleotides on poly-L-lysine coated glass slides by Gene Machines robotics (Omnigrid, San Carlos, CA). We have followed the MIAME (minimum information about a microarray experiment) guidelines for the presentation of our data [21].

\section{Probe preparation}

Total human universal RNA (HuURNA) isolated from a collection of adult human tissues to represent a broad range of expressed genes from both male and female donors (BD Biosciences, Palo Alto, CA) serve as a universal reference control in the competitive hybridization. All examined samples are hybridized against HuURNA. The correlation coefficients among those biological repeats themselves are consistently $\geq 0.8$, which documented the quality of hybridization and consistency of expression among the replicates of all examined erythroid progenitors. Labeled cDNA probes are produced as described [22]. Briefly, $5 \mu \mathrm{g}$ of total RNA is incubated at $70^{\circ} \mathrm{C}$ for 5 minutes along with $1 \mu \mathrm{l}$ of aminoallyl-oligo dT primer and quickly chilled for 3 minutes. Then, $2 \mu \mathrm{l} 10 \mathrm{X}$ first strand buffer, $1.5 \mu \mathrm{l}$ SSII enzyme (Stratagene, La Jolla, CA), $1.5 \mu \mathrm{l} 20 \mathrm{X}$ aminoallyl dUTP and $2 \mu \mathrm{l}$ of $0.1 \mathrm{M}$ DTT are added and incubated for 90 minutes at $42^{\circ} \mathrm{C}$. After incubation, volume of the reaction mixture is raised to $60 \mu \mathrm{l}$ with $40 \mu \mathrm{l}$ of DEPC water. cDNA is purified by the MinElute column (Qiagen). $300 \mu$ l of Binding buffer $\mathrm{PB}$ is added to the coupled cDNA, and the mixture applied to the MinElute column, and centrifuged for $1 \mathrm{mi}$ nute at $10.000 \mathrm{rpm}$. After discharging the flow-through, $600 \mu \mathrm{l}$ of washing buffer PE is added to the column, and centrifuged for 1 minute at $10.000 \mathrm{rpm}$. The flowthrough is discharged and the washing repeated. Then the columns are placed into a fresh eppendorf tube and $15 \mu \mathrm{l}$ elution buffer added to the membrane, incubated for 1 minute at room temperature, centrifuged for $1 \mathrm{mi}$ nute at $10.000 \mathrm{rpm}$ and probe collected. The probe is dried in speed-vac for 16 minutes. Finally, $5 \mu \mathrm{l}$ of $2 \mathrm{X}$ coupling buffer and $5 \mu \mathrm{l} \mathrm{Cy} 3$ and Cy 5 dye (GE Healthcare Bio-Sciences Corp., Piscataway, NJ) are mixed into the control (HuURNA) and experimental cDNAs (huES cell-derived) respectively and incubated at room temperature in dark for 90 minutes. After incubation, the volume is raised to $60 \mu \mathrm{l}$ by $50 \mu \mathrm{l} \mathrm{DEPC}$ water and then cDNA is purified by the MinElute column and eluted with $13 \mu$ l elution buffer by centrifugation.

\section{Hybridization}

For hybridization, $36 \mu \mathrm{l}$ hybridization mixture [26 $\mu \mathrm{l}$ cDNA mixture, $1 \mu \mathrm{l}(10 \mu \mathrm{g})$ COT-1 DNA, $1 \mu \mathrm{l}(8-10$ $\mu \mathrm{g})$ poly $(\mathrm{dA}), 1 \mu \mathrm{l}$ yeast total RNA $(4 \mu \mathrm{g}), 6 \mu \mathrm{l} 20 \mathrm{X}$ SSC and $1 \mu \mathrm{l} 10 \% \mathrm{SDS}$ ] is pre-heated at $100^{\circ} \mathrm{C}$ for 2 minutes and cooled for 1 minute. Total volume of probe is added on the array and covered with cover slip. Slides are placed in hybridization chamber and $20 \mu \mathrm{l}$ water is added to the slide, and incubated overnight at $65^{\circ} \mathrm{C}$. Slides are then washed for 2 minutes each in $2 \mathrm{X} \mathrm{SSC}$, 1X SSC and 0.1X SSC and spin-dried.

\section{Data filtration, normalization, and analysis}

Microarray slides are scanned in both Cy3 (532 nm) and Cy5 (635 nm) channels using Axon GenePix 4000B scanner (Axon Instruments, Inc., Foster City, CA) with a 10 -micron resolution. Scanned microarray images are exported as TIFF files to GenePix Pro 3.0 software for image analysis. The raw images are collected at 16-bit/ pixel resolutions with 0 to 65,535 count dynamic range. The area surrounding each spot image is used to calculate a local background and subtracted from each spot before the Cy5:Cy3 ratio calculation. The average of the total $\mathrm{Cy} 3$ and $\mathrm{Cy} 5$ signal gives a ratio that is used to normalize the signals. Each microarray experiment is globally normalized to make the median value of the log2-ratio equal to zero. The Loess normalization process corrects for dye bias, photo multiplier tube voltage imbalance, and variations between channels in the amounts of the labeled cDNA probes hybridized. The data files representing the differentially expressed genes are then created. For advanced data analysis, gpr and jpeg files are imported into microarray database, and normalized by software tools provided by NIH Center for Information Technology (http://nciarray.nci.nih.gov/). Spots with confidence interval of 99 ( $\geq 2$ fold) with at least 150-fluorescence intensity for both channel and $30 \mu \mathrm{m}$ spot size are considered as good quality spots for 
analysis. We gathered a set of 8,719 erythroid cells gene expression data derived from 11 datasets that have been posted on the National Center for Biotechnology Information (NCBI) Gene Expression Omnibus (GEO) database.

\section{Statistical analysis}

The one way ANOVA with Tukey's Multiple Comparison tests and paired t test are applied using Prism 4 software (GraphPad Software Inc., San Diego, CA) for measurement of statistical significance in microarray analysis during ontogenesis. Ingenuity Pathways Analysis is a software application that enables identification of the biological mechanisms, pathways and functions most relevant to the genes of interest [www.ingenuity.com].

\section{Results}

Gene expression patterns in erythroid progenitor cells during ontogeny

In the presence of EPO and other cytokines, CD34 hematopoietic progenitor cells are differentiated in vitro into erythroid progenitor cells. We already reported the steady increase in adult hemoglobin and decline in fetal hemoglobin levels during in vitro erythroid differentiation of PB CD34 ${ }^{+}$cells [20]. At day 6 of erythroid cell culture, the erythroid progenitor cells of examined ontological stages are labeled as $100 \% \mathrm{CD}^{+}{ }^{+}$(a well-known early marker of erythroid differentiation) are isolated for microarray analysis. Moreover, we perform flow cytometry of three additional differentiation markers CD34, CD36 and glycophorin A and despite variation in their expression we did not find the statistical significance at day 6 of erythroid culture (not shown). The total number of expressed genes per ontogenic stage, evaluated by microarray analysis, is presented in Table 1 (first column). The microarray data discussed in this publication we deposited in NCBI's GEO database and are accessible through GEO Series accession number GSE37869 (http:// www.ncbi.nlm.nih.gov/geo/query/acc.cgi?acc=GSE37869). Presence of individual genes in two-thirds of examined samples per cell group (66\% filtering) reduced largely the total gene expression (second column, Table 1). The total gene expression is more than doubled in erythroid

Table 1 Number of total genes in examined cells and quantification of overexpressed genes versus HuURNA

\begin{tabular}{cccccc}
\hline $\begin{array}{c}\text { Filtering } \\
\text {-derived cells }\end{array}$ & $\begin{array}{c}\text { No } \\
\text { total }\end{array}$ & total & \multicolumn{3}{c}{$66 \%$} \\
\cline { 3 - 6 } & & & $\geq 1.5$ fold & $\geq 2$ fold & $\geq 3$ fold \\
\hline FL & 5900 & 1755 & 150 & 43 & 10 \\
\hline CB & 6667 & 3844 & 325 & 84 & 14 \\
\hline BM & 7002 & 1770 & 247 & 90 & 13 \\
\hline PB & 3794 & 1325 & 83 & 29 & 2 \\
\hline
\end{tabular}

$F L$-fetal liver, $C B$-cord blood, $B M$-bone marrow, $P B$-peripheral blood. progenitor cells of CB-derived cells in comparison to other cells. Adult PB-derived erythroid progenitor cells express the least quantity of genes. A total of 43 genes were highly expressed (two-fold and higher) in FL, 84 genes in CB, 90 in $\mathrm{BM}$, and 29 genes in $\mathrm{PB}$-derived erythroid progenitor cells (Table 1). Overexpression of 1011 genes is common in all cells during ontogeny (after 66\% filtering). In addition to globins, the common highly expressed genes in erythroid progenitor cells are proteoglycan 2 (PRG2), Charcot-Leyden crystal protein $(C L C)$, serglycin $(S R G N)$, eosinophil peroxidase $(E P X)$ and $M Y C$. To examine effect of FBS on erythropoiesis, we decide to follow erythropoietic markers $\gamma$ and $\beta$ globins in the same in vitro erythroid culture conditions with or without FBS. However, the reduction of $\gamma$ globin gene expression and $\gamma / \beta$ ratio did not reach statistical significance in FBS-deprived culture conditions (not shown).

\section{Microarray analysis of gene expression profiles in erythroid progenitor cells}

To distinguish genes with statistically significant expression in erythroid progenitors through ontogeny we perform comparisons using the t-test (Table 2-4). During microarray analysis genes are upregulated or downregulated compared to HuURNA, used as a control alongside each sample. We present upregulated genes compared to HuURNA determined by t-test in Table 2 . The other statistically significant genes that have the same pattern of expression, as genes in Table 2, are presented in Additional file 1. The ERAF gene related to erythroid differentiation and hematological system development is upregulated in BM tissue (Table 2). The same patterns of expression and ratio as ERAF gene are also observed for the following genes: ENY2, GSTO1, HMGB2, HPS4, HSD17B10, METTL13 (Additional file $1)$. We also separate downregulated genes compared to HuURNA determined by t-test (Table 3, Additional file $2)$. The same pattern of expression, statistical significance and ratio as GNB1 gene, elevated in CB-derived cells, is also observed for the CYB5R3, ILF3 and NKX2-5 genes. The same patterns of expression and ratio as PDGFRA gene, upregulated in BM tissue, are also observed for the ERGIC1 and RAPSN genes (Additional file 2). Some genes are differentially upregulated and downregulated in various stages, so we present them as special group of diverse genes in statistical analysis by t-test (Table 4, Additional file 3). STAT5A and STAT5B have the highest gene expression in BM-derived erythroid cells (Tables 2). The same patterns of expression, statistical significance and ratio as $S T A T 5 B$ gene are observed for the following genes: HIGD1A, KHSRP, LYSMD3, SF1, SPEN, ACOT9, TACC3, VDAC2. Besides statistical analysis performed by t-test between two group of cells, we also make ANOVA analysis of the 
Table 2 Statistically significant genes by t-test up-regulated vs. HuURNA among examined cells. $\mathbf{p}<\mathbf{0 . 0 1}$ $(\leq, \geq), \mathbf{p}<0.05(<,>)$

\begin{tabular}{llc}
\hline $\begin{array}{l}\text { Gene } \\
\text { Name }\end{array}$ & Description vs. & F F F C C B \\
\hline ABCE1 & ATP-binding cassette, sub-family E memb. 1 & C B P B P P \\
\hline
\end{tabular}

\begin{tabular}{lll}
\hline ACLY & ATP citrate lyase & $>$ \\
\hline AP1B1 & adaptor-related protein complex1, $\beta 1$ subunit $><$
\end{tabular}

$\begin{array}{lll}\text { AP1B1 } & \text { adaptor-related protein complex1, } \beta 1 \text { subunit }><\end{array}$

BAT2D1 BAT2 domain containing $1>>$

\begin{tabular}{llll}
\hline BTF3L3 & basic transcription factor 3-like 3 & $<$ \\
\hline CAPZA2 & capping protein (actin fil.) muscle Z-line, a2 & $\leq$
\end{tabular}

CAPZA2 capping protein (actin fil.) muscle Z-line, a2 $\leq$

\begin{tabular}{lll}
\hline CLK2 & CDC-like kinase 2 & $>$ \\
\hline CORO1C & coronin, actin binding protein, 1 C & $><>$
\end{tabular}

CSDE1 cold shock domain containing E1, RNA-bind $<$

DDOST dolichyl-diphosphooligos-prot glycosyltransf $\quad>>>$

ECH1 enoyl Coenzyme A hydratase 1 peroxisomal $\leq \leq$

ENO1 enolase 1, (alpha) >

ERAF erythroid associated factor $<$

FADS2 fatty acid desaturase $2<<$

GOLIM4 golgi integral membrane protein $4 \leq$

\begin{tabular}{lll}
\hline HDAC1 & histone deacetylase 1 & \\
\hline HSPA5 & heat shock $70 \mathrm{kDa}$ protein 5 & $>\geq$
\end{tabular}

HSPA8 heat shock $70 \mathrm{kDa}$ protein $8 \quad>$

\begin{tabular}{lll}
\hline LDHA & lactate dehydrogenase A & $>>>$ \\
\hline MYBL2 & v-myb myeloblastosis viral oncog hom-like 2 & $<$
\end{tabular}

MYBL2 v-myb myeloblastosis viral oncog hom-like 2 <

\begin{tabular}{lll}
\hline NDUFAB1 NADH dehydrog ubiquinone 1 a/ $\beta$ subcomp1 $<<$ \\
\hline NFATC3 & nucl fact of activ T-cel cytopl calcineur-dep $3<<$
\end{tabular}

\begin{tabular}{llc}
\hline PDIA6 & protein disulfide isomerase family A m6 & $>$ \\
\hline PPA1 & pyrophosphatase (inorganic) 1 & $<$ \\
\hline PSMB3 & proteasome (prosome) subunit, $\beta$ type, 3 & $>$
\end{tabular}

\begin{tabular}{lll} 
PSMB3 & proteasome (prosome) subunit, $\beta$ type, 3 & $>$ \\
\hline RPL18A & ORF & $><$
\end{tabular}

\begin{tabular}{ll} 
RPN1 ribophorin I & $>\geq$ \\
\hline SERPINB1 serpin peptidase inhibitor, clade B m1 & $\geq \geq$
\end{tabular}

SERPINB1 serpin peptidase inhibitor, clade B m1 $\geq \geq$

\begin{tabular}{lll}
\hline STAT5A & Signal transd. and activator of transcript. 5A & $<<$ \\
\hline TFDP3 & transcription factor Dp family, member 3 & $\leq<$ \\
\hline
\end{tabular}

TIMM23 transl of inner mitoch memb 23 hom ngemp $<$

\begin{tabular}{llc}
\hline TPST2 & tyrosylprotein sulfotransferase 2 & $<$ \\
\hline TUBG1 & tubulin, gamma 1 & $<\leq$
\end{tabular}

TXNL1 thioredoxin-like $1<<$

YWHAZ tyrosine 3-/tryptophan 5-monooxygenase zeta pp $<\leq>$

ZNF224 zinc finger protein $224 \leq<$

ZNF43 zinc finger protein $43<>$

nuclear gene encoding mitochondrial protein (ngemp), member $(\mathrm{m})$. Bolded genes - expression $>1.5$ fold vs. HuURNA; $F$-fetal liver, $C$-cord blood, $B$-bone marrow, $P$-peripheral blood.

common genes among all four ontogenic stages and present them in Additional file 4. This extended statistical analysis also reveal that HDAC1 and SERPINB1 genes are significantly increased in FL-derived erythroid progenitor cells (Tables 2). HDAC2 gene expression is largely increased throughout ontogeny with the highest level also in FL-derived cells (not shown). Apoptotic IGFBP7 gene is downregulated, mostly in adult derived cells (Table 3). In addition, these ANOVA determined genes are also shown in hierarchical clustering analysis, as well as clustering of individual samples of all examined cells (Figure 1).

\section{Pathways linked to hematological system development}

Using the Ingenuity Pathways Analysis software, we evaluate the network pathway of genes linked to hematological system development (Figure 2). As shown in Figure 2, KITLG (SCF), EPO, GATA1 and STAT3 represent the major junction points in hematological system development. The effects of KITLG are only indirect toward other related molecules, whereas STAT3 is the major target point for direct or indirect effects of linked molecules (Figure 2). In our microarray analysis, KITLG and $E P O$ gene expression are downregulated in BM- and PB-, whereas STAT3 gene expression is slightly upregulated in erythroid progenitor cells and more notably in CB- and BM-derived cells. GATA1 gene expression is considerably upregulated in all cells during ontogeny, except a low level in FL-derived cells. KITLG and EPO linked ERAF and UCP2 gene expression are increased during ontogeny, but reached maximum in adult derived cells (Table 2, Additional file 1). The expression of genes related to hematological system development throughout ontogeny (Figure 2) have the following characteristics: WDR1 gene expression, induced by EPO and KITLG, is decreased only in PB-derived cells, with the top level in erythroid progenitor cells of FL origin (Table 4). EPX gene expression is significantly upregulated in FL- and CB-derived erythroid cells compared to PB-derived cells. Rh-associated glycoprotein (RHAG) has decreased expression in $\mathrm{BM}-$, whereas cytokine inducible $\mathrm{SH} 2-$ containing protein $(\mathrm{CISH})$ and PIM1 have increased expression in BM- and PB-derived erythroid cells. CLC, colony stimulating factor 3 receptor (CSF3R), cleavage and polyadenylation specific factor 3 (CPSF3) and small GTP binding protein $(R A B 4 A)$ genes have increased expression, whereas thioredoxin-like 1 (TXNL1) has decreased expression in FL-derived erythroid progenitor cells. EPO receptor $(E P O R)$ gene expression is increased in CB- and BM-derived erythroid cells. Regarding succinate dehydrogenase complex gene expression, subunit A $(S D H A)$ is also increased in FL-, subunit B $(S D H B)$ in $\mathrm{CB}$ - and $\mathrm{BM}-$-, subunit $\mathrm{D}(S D H D)$ in $\mathrm{PB}-$, while subunit $\mathrm{C}(\mathrm{SDHC})$ is decreased in BM-derived erythroid cells.

\section{Proliferation and survival of erythroid cells}

EPO stimulates the JAK-STAT pathway during erythroid differentiation [16]. We also use EPO for erythroid 


\begin{tabular}{|c|c|c|c|c|}
\hline \multirow{2}{*}{$\begin{array}{l}\text { Gene } \\
\text { Name }\end{array}$} & \multirow[t]{2}{*}{ Description vs. } & \multicolumn{3}{|c|}{$F$ F F C C B } \\
\hline & & C B & $\mathrm{P}$ & B P P \\
\hline ADRB3 & adrenergic, $\beta-3-$, receptor & & & $<$ \\
\hline ATP6C & ATPase, $\mathrm{H}+$ transporting, lysosomal $16 \mathrm{kD}$ & $<$ & & $>$ \\
\hline BTBD10 & BTB (POZ) domain containing 10 & $\leq$ & & \\
\hline BTRC & beta-transducin repeat containing & & & $>$ \\
\hline CABP2 & Calcium binding protein 2 & & & $>$ \\
\hline CLEC4E & C-type lectin domain family 4, member $\mathrm{E}$ & $\geq$ & $\geq \geq$ & $>$ \\
\hline COQ10B & coenzyme Q10 homolog B (S. cerevisiae) & & & $<$ \\
\hline DVL3 & dishevelled, dsh homolog 3 & & & $<$ \\
\hline $\mathrm{F} 2 \mathrm{R}$ & coagulation factor II (thrombin) receptor & & & $>$ \\
\hline FPR1 & $\mathrm{N}$-formylpeptide receptor fMLP-R98 ORF & & $>$ & \\
\hline GSTM1 & glutathione S-transferase mu 1 & & $>$ & \\
\hline IGFBP7 & insulin-like growth factor binding protein 7 & & $\geq$ & $>>$ \\
\hline MINK1 & Misshapen-like kinase 1 (zebrafish) & & $<$ & \\
\hline MT1A & metallothionein $1 \mathrm{~A}$ & $<$ & & \\
\hline NPIPL3 & nuclear pore complex interact. protein-like 3 & & $<$ & \\
\hline PDGFRA & platelet-derived growth factor receptor, a & & & $<$ \\
\hline PDLIM1 & PDZ and LIM domain 1 & $<$ & & $\geq>$ \\
\hline PHLDA1 & pleckstrin homology-like domain family A m1 & & & $>$ \\
\hline PSMC4 & proteasome (prosome) $26 \mathrm{~S}$ sub, ATPase, 4 & & & $>$ \\
\hline SP2 & Sp2 transcription factor & $>$ & $>>$ & \\
\hline SQSTM1 & sequestosome 1 & & $<$ & $<$ \\
\hline ST3GAL1 & ST3 $\beta$-galactoside $\alpha$-2,3-sialyltransferase 1 & & & $<$ \\
\hline TIMP3 & TIMP metallopeptidase inhibitor 3 & $>>$ & $>>$ & $>$ \\
\hline UBE2D3 & ubiquitin-conjugating enzyme E2D 3 & $<$ & K & \\
\hline UBXN1 & UBX domain protein 1 & & & $<$ \\
\hline VAT1 & vesicle amine transport protein 1 homolog & & $>$ & $>$ \\
\hline
\end{tabular}

nuclear gene encoding mitochondrial protein (ngemp), member (m). Bolded genes - expression $>1.5$ fold vs. HuURNA. F-fetal liver, $C$-cord blood, $B$-bone marrow, P-peripheral blood.

differentiation of $\mathrm{CD} 34^{+}$hematopoietic progenitor cells in liquid cultures. We present JAK-STAT signaling pathway related gene expression in Figure 3, as determined by microarray analysis. Some JAK-STAT pathway related genes are persistently upregulated throughout ontogeny (PIM1, SOCS2, MYC, PTPN11), while others are downregulated (PTPN6, PIAS3 and 4, SPRED2). Besides these steady genes, some JAK-STAT pathway related genes are variously regulated during ontogeny (STATs, GRB2, $C R E B B$, etc.). STAT1 and STAT5A gene expression is upregulated throughout ontogeny reaching maximum in erythroid progenitors of BM origin. STAT5B and STAT6 gene expression is downregulated in most ontogenic stages reaching slightly positive values only in erythroid progenitors of BM- and FL-derived cells, respectively. The growth factor receptor-bound protein 2 (GRB2) demonstrates upregulation in erythroid cells of $\mathrm{FL}$ and $\mathrm{BM}$ origin compared to its downregulation in $\mathrm{CB}-$ and PB-derived cells. The enzymes phosphoinositide-3-kinase (PIK3), catalytic, gamma polypeptide (PIK3CG) and PIK3, regulatory subunit 2 (PIK3R5) are downregulated in all hematopoietic cells during ontogeny, whereas PIK3R2 is downregulated only in BM-derived cells and upregulated in other hematopoietic cells. CREB binding protein (CREBBP) gene expression is absent in PB-, but has the highest elevation in FL- and CB-derived erythroid cells. BCL2-like 1 (BCL2L1) gene expression is downregulated in CB-derived cells and increased in other cells, mostly in PB-derived erythroid cells. SOS1 gene expression is increased in $\mathrm{CB}$ - and $\mathrm{BM}$-derived cells.

Phosphorylation of AKT, a signaling molecule downstream of PI3K, is observed following SCF treatment [16]. We use SCF in medium of our liquid cultures to induce erythroid differentiation of hematopoietic progenitors, together with EPO and cocktail of cytokines. We present PI3K-AKT signaling pathway related gene expression in Figure 4, as determined by microarray analysis. Beside continuously upregulated (AKT1, PPP2CA, CHUK, NFKB1, etc) and downregulated (FOXO1, PDPK1, PIK3CG) genes in the PI3K-AKT signaling pathway, we observe intermittently regulated gene expression (YWHAH, NFKBIA). Tyrosine 3-monooxygenase/ tryptophan 5-monooxygenase activation protein (YWHAH) gene expression is absent in erythroid progenitors of $\mathrm{FL}$ origin, downregulated in $\mathrm{CB}$ - and $\mathrm{BM}-$, and not changed in PB-derived cells. Nuclear factor of kappa light polypeptide gene enhancer in B-cells inhibitor, alpha (NFKBIA) gene expression is upregulated in erythroid progenitors of $\mathrm{CB}$ origin, downregulated in FL- and $\mathrm{BM}-$, and not changed in PB-derived cells. HSP90AA1 has the most increased expression of all PI3K-AKT pathway related genes, continuously increasing expression from fetal- to adult-derived erythroid cells. In contrast, upregulated $P P P 2 C A$ gene expression demonstrates continuous decrease from fetal- to adult-derived erythroid cells.

\section{Discussion}

We present the number of genes overexpressed in erythroid progenitor cells from several ontogenic stages. The total gene expression in erythroid progenitor cells of CB-derived tissues is twice that in other examined cells. These erythroid progenitor cells share 1011 common genes in cells derived from all examined ontogenic stages. We perform statistical analysis of the common genes among examined ontogenic stages and determine significant HDAC1 and SERPINB1 upregulation in FLderived and significant ERAF, STAT5A upregulation in adult cells-derived erythroid progenitors. ERAF gene expression is directed by EPO and SCF activity, while STAT5A promote proliferation and growth of erythroid 
Table 4 Statistically significant by t-test genes down- $/$ up-regulated vs. HuURNA among examined cells. $p<0.01$ $(\leq, \geq), \mathbf{p}<0.05(<,>)$

\begin{tabular}{lr}
\hline $\begin{array}{l}\text { Gene } \\
\text { Name }\end{array}$ & Description vs. \\
\hline ATP6V1B2 ATPase, H + transport, & C B P P B P P \\
\hline
\end{tabular}
lysosomal 56/58 kDa, V1 sub B2

\begin{tabular}{|c|c|c|c|c|}
\hline BRP44 & brain protein 44 & $<$ & $\leq$ & $\leq$ \\
\hline CD24 & CD24 molecule & \multicolumn{3}{|c|}{$>>$} \\
\hline CDK2AP2 & $\begin{array}{l}\text { cyclin-dependent kinase } 2 \\
\text { associated prot. } 2\end{array}$ & \multicolumn{2}{|l|}{$>$} & $<<$ \\
\hline CLTA & clathrin, light chain (Lca) & \multicolumn{3}{|c|}{$\leq$} \\
\hline COMT & catechol-O-methyltransferase & \multicolumn{3}{|c|}{$\geq \quad \geq$} \\
\hline COR01A & coronin, actin binding protein, $1 \mathrm{~A}$ & \multicolumn{3}{|c|}{$\geq$} \\
\hline GADD45A & $\begin{array}{l}\text { growth arrest and } \\
\text { DNA-damage-inducible a }\end{array}$ & \multicolumn{3}{|c|}{$<<$} \\
\hline ITGB2 & integrin, beta 2 & \multicolumn{3}{|r|}{$>$} \\
\hline KIFC1 & HSET mRNA for kinesin-related protein & \multicolumn{3}{|c|}{$<$} \\
\hline LSR & lipolysis stimulated lipoprotein receptor & \multicolumn{3}{|c|}{$\geq$} \\
\hline PSMB6 & $\begin{array}{l}\text { proteasome (prosome) subunit, } \\
\beta \text { type, } 6\end{array}$ & \multicolumn{3}{|c|}{$<$} \\
\hline SMAP2 & small ArfGAP2 & \multicolumn{3}{|c|}{$<<$} \\
\hline SMARCA2 & $\begin{array}{l}\text { SWI/SNF related, matrix associated, } \\
\text { actin depend regul of chromat, } \\
\text { subfam a, memb } 2\end{array}$ & \multicolumn{3}{|c|}{$>$} \\
\hline STAT6 & $\begin{array}{l}\text { signal transd \& activat of transcr } 6 \text {, } \\
\text { IL-4 ind }\end{array}$ & \multicolumn{3}{|c|}{$>\geq$} \\
\hline THYN1 & thymocyte nuclear protein 1 & \multicolumn{3}{|c|}{$<$} \\
\hline $\mathrm{TMX} 2$ & thioredoxin-related transmembrane protein 2 & \multicolumn{3}{|c|}{$<$} \\
\hline TPSB2 & tryptase beta 2 & $<$ & \multicolumn{2}{|c|}{$<<$} \\
\hline VASP & vasodilator-stimulated phosphoprotein & \multicolumn{3}{|c|}{$\geq$} \\
\hline VIM & vimentin & \multicolumn{3}{|c|}{$>>$} \\
\hline WDR1 & WD repeat domain 1 & & $\geq$ & $>\geq$ \\
\hline$\overline{X B P 1}$ & $\mathrm{X}$-box binding protein 1 & \multicolumn{3}{|c|}{$>\geq>\geq$} \\
\hline
\end{tabular}

nuclear gene encoding mitochondrial protein (ngemp), member (m). Bolded genes - expression >1.5 fold vs. HuURNA. F-fetal liver, C-cord blood, B-bone marrow, P-peripheral blood.

cells through JAK-STAT pathway. We also perform functional categorization by Ingenuity Pathways analysis with the network of genes linked to hematological system development. This analysis reveal the KITLG, EPO, GATA1, PIM1 and STAT3 genes as the most important interaction points for activity of related genes involved in hematological development.

We focus our presentation of microarray results on pathways linked to hematological system development, cellular growth and proliferation. Besides already mentioned meeting point genes (GATA1, EPO), we describe genes differentially expressed in some stages of ontogeny (ERAF, PIM1). The phosphorylation of GATA1 is important for EPO-induced maturation of fetal liver erythroid progenitor cells [23]. The role of GATA1 in terminal erythroid differentiation includes suppression of GATA2 expression and upregulation of erythroidspecific target genes including those for KLF1, NFE2 and EPOR. GATA1 gene expression was low in our FLderived erythroid cells, in contrast to other stages of ontogeny. ERAF is an erythroid-specific protein, with low levels in erythroid cells of FL-origin and high levels in BM-derived cells. In addition, HDAC1 and HDAC2 stimulation of cell proliferation is mediated by STAT3 [24], while HDACs gene expression is elevated in erythroid progenitors during ontogeny demonstrating importance in early stages of ontogeny. PIM family genes have a role in signal transduction in blood cells, contributing to both cell proliferation and survival. A recent report suggests that the PIM family genes, implicated in cytokine-dependent signaling in hematopoietic cells, are related to RUNX genes which regulate cell proliferation and differentiation in ontogeny [25]. Runx1 is reported to play an early role in hematopoietic development, and we detect its increased gene expression in CB-derived erythroid cells [26].

According to previous reports, the PI3K-AKT signaling pathway regulates EPO-induced survival, proliferation, and maturation of early erythroid progenitors $[27,28]$. PI3K prevents apoptosis and stimulate cell proliferation in response to EPO stimulation in erythroid progenitors [29]. Both EPO and SCF induce activation of PI3K, moreover SCF causes activation of anti-apoptotic AKT, a signaling molecule downstream of PI3K [16,30]. In presented AKT signaling pathway, we demonstrate that CB-derived erythroid cell survival is related to upregulated NFKBIA gene, while FL-derived erythroid cell survival is linked to upregulated NFKB1 and PPP2CA genes. Moreover, $\mathrm{BM}$ - and $\mathrm{PB}$-derived erythroid cell survival is associated with elevated HSP90AA1 gene expression.

Influence of FBS and cytokines on in vitro erythropoiesis has been observed in previous studies. It has been studied GM-CSF and IL-3 effects on adult human erythroid progenitors, stimulated to terminal differentiation by EPO, under FBS-supplemented or FBS-deprived culture conditions. Although hemoglobinization and maturation of BFU-E-derived erythroblasts was comparable in FBS-replete versus FBS-deprived cultures, the latter had significantly less $\gamma$-globin gene expression. Factors present in FBS appear to exert a dominant influence on fetal globin synthesis in vitro [31]. Both GM-CSF and IL-3 exhibit erythroid burst-promoting activity in FBSdeprived cultures, but IL-3 is more active [32]. Fetal calf serum (FCS) is known to elevate $\gamma$-globin mRNA levels and fetal hemoglobin in BFU-E culture; removal of FCS from the BFU-E cultures did not significantly reduce $\gamma$ globin mRNA levels [33]. FCS factors, responsible for fetal hemoglobin increase, act at both early and late stages of erythroid differentiation [34]. 


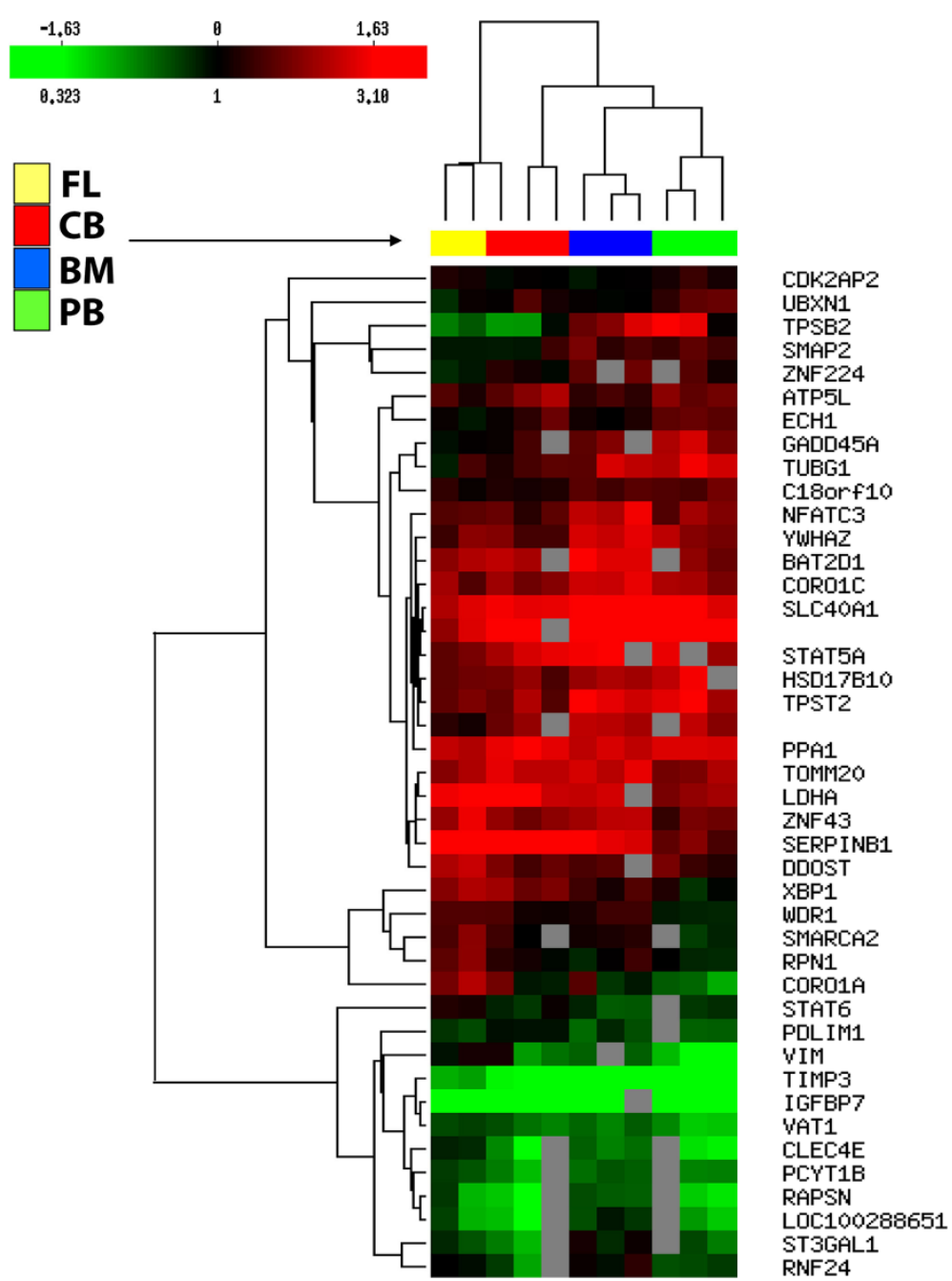

Figure 1 Hierarchical clustering of genes expressed during ontogeny. Hierarchical clustering of statistically significant genes determined by ANOVA and expressed during ontogeny (left side). The color indicates the relative fold expression of each gene, with red indicating higher expression, green indicating negative expression, black representing not changed expression, while gray stands for absent expression per each examined sample. The total gene expression of erythroid progenitor cells from various cells is also clustered (above image) representing similarities among various cells.

A recent report revealed that a persistent activation of transcription factor/signaling protein STAT5A in human hematopoietic stem and progenitor cells favored their erythroid differentiation [35]. Increased STAT5A gene expression is present throughout ontogeny and reached a peak in BM-derived erythroid cells. The tyrosine phosphorylation of STAT5, a downstream target for the non-receptor tyrosine kinase, JAK2, is mediated by EPO [16,17]. The EPOR gene has more than double expression in CB-derived erythroid cells in comparison to PB-derived cells according to our microarray analysis. CREB1 is significantly elevated only in erythroid progenitor cells of FL origin, compared to other ontogenic stages. The protein tyrosine phosphatase family (PTP) contains signaling molecules that regulate cell growth and differentiation. PTPN11 gene expression is elevated throughout ontogeny, reaching maximum in erythroid progenitors of BM origin. According to JAK-STAT pathway related gene expression in erythroid progenitors during different periods of ontogeny, we demonstrate the antiapoptotic mechanism regulated by PIK3R2 (increased in fetal derived cells) and $B C L 2 L 1$ (increased in adult derived cells). The same apply for growth and proliferation where largely increased PIM1, STAT1 and STAT5A gene expression is present throughout ontogeny and particularly in BM-derived erythroid progenitors. MAPK signaling pathway has been regulated by PTPN11 (BM-derived), GRB2 (FL- and BM-derived) and SOS (CB-derived cells) gene interaction. 


\section{The genes expressed in:}

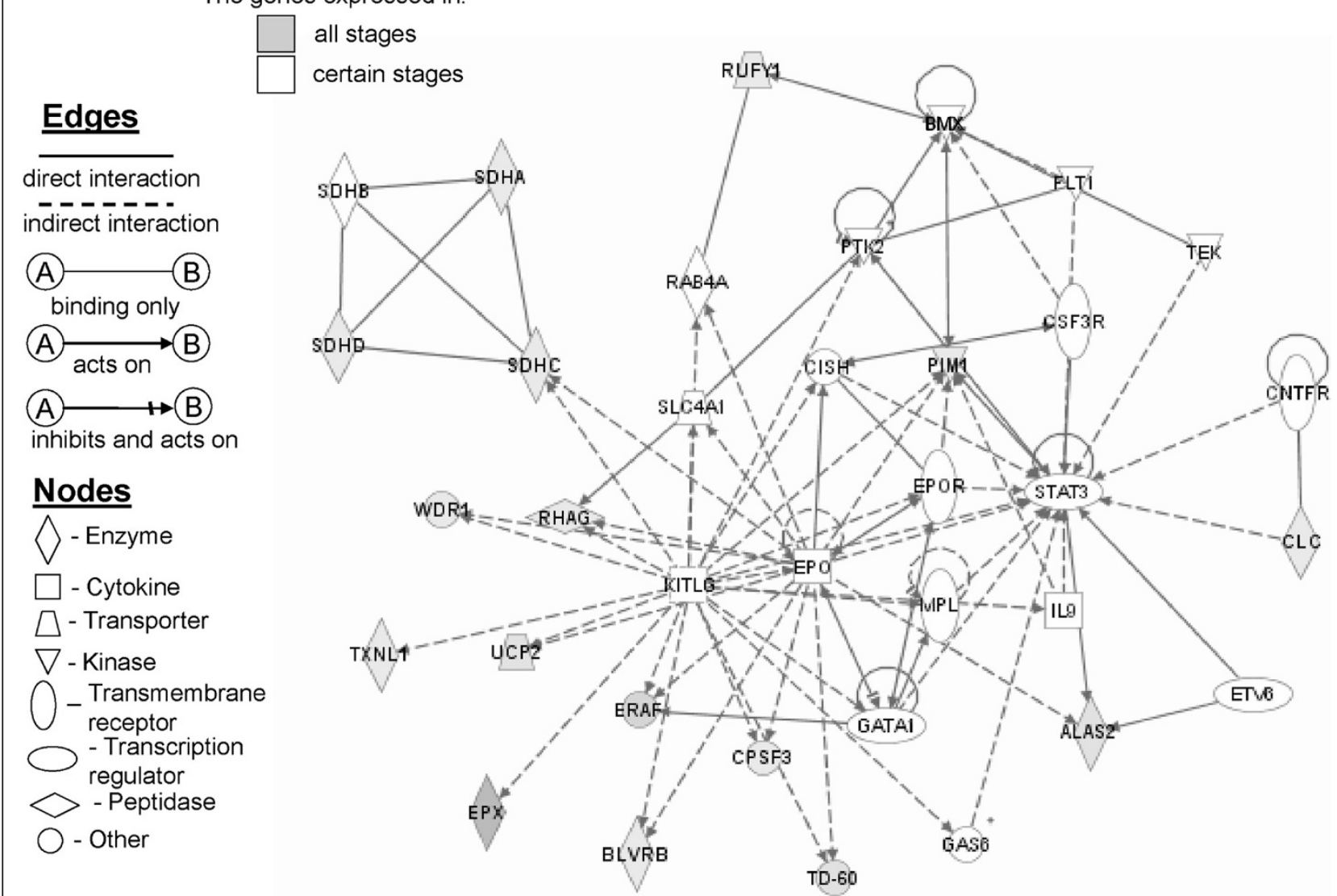

Figure 2 Hematological system development, cellular growth and proliferation. Using Ingenuity Pathways Analysis software we created the network pathway of genes related to hematological system development. White nodes represent expressed genes in some stages, while gray nodes represent genes expressed in all stages throughout ontogeny. The intensity of gray color is in positive correlation with a level of gene expression in erythroid progenitors.

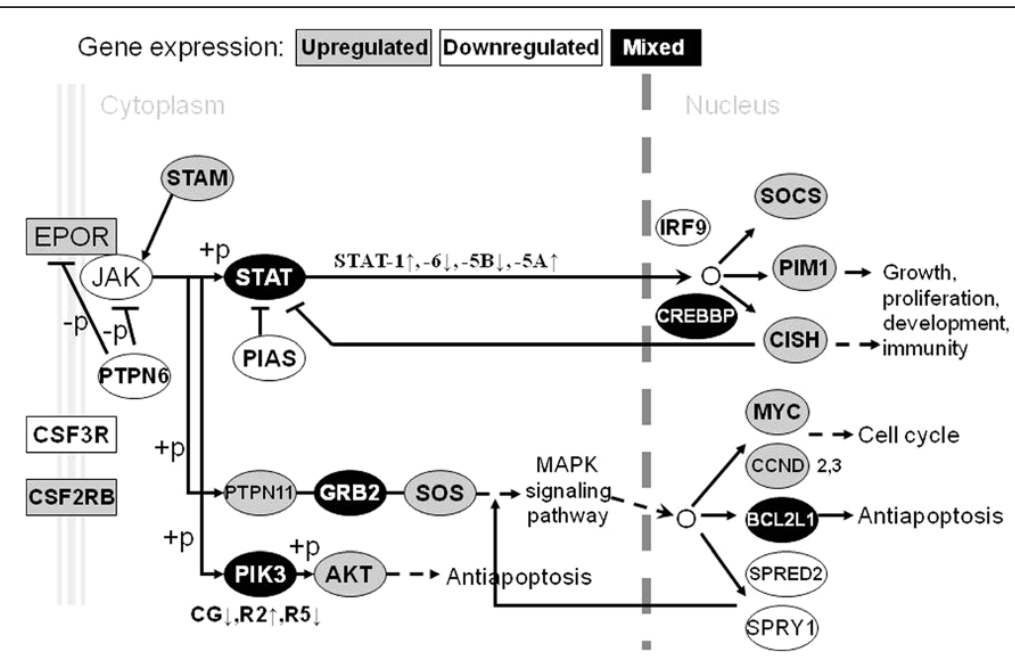

Figure 3 JAK-STAT signaling pathway. The expression of genes linked to JAK-STAT signaling pathway through ontogeny. (+p) phosphorylation, $(-p)$ dephosphorylation, $\rightarrow$ stimulation, $\perp$ inhibition, $\rightarrow$ translocation, $\downarrow$ decreased gene expression, $\uparrow$ increased gene expression. 


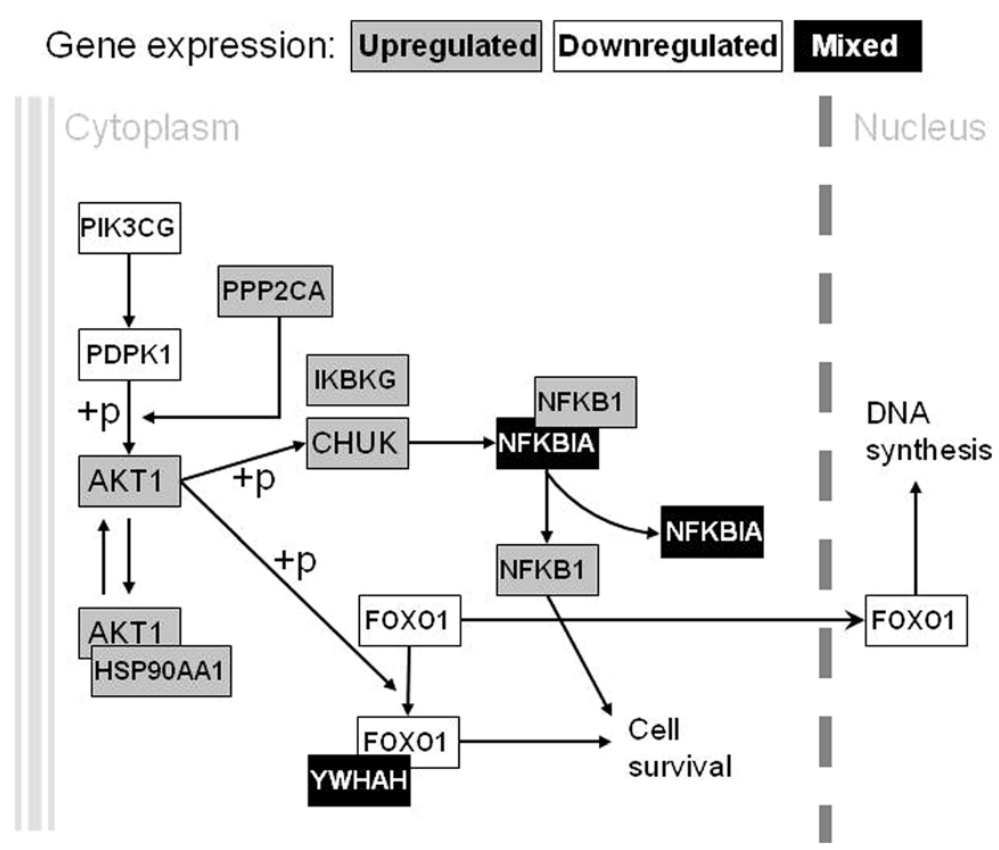

Figure 4 AKT signaling pathway. The expression of genes linked to AKT signaling pathway through ontogeny. (+p) phosphorylation, $\rightarrow$ stimulation, $\rightarrow$ translocation.

\section{Conclusions}

This ontogenic overview of specific genes and transcriptional programs in normal erythropoiesis may contribute to understanding of erythropoietic progenitor cell development. It may form the basis for modifications of gene expression in any kind of hematological malignancies as well as in other diseases affecting erythropoiesis, and more broadly, hematopoiesis. It will be important to extend this study of analyzed signaling pathways, from the gene expression level to protein expression and phosphorylation levels. Affirmation of examined genes on both levels will support the significance of our results.

\section{Additional files}

Additional file 1 Statistically significant by t-test genes up-regulated vs. HuURNA among examined cells.

Additional file $\mathbf{2}$ Statistically significant by t-test genes down-regulated vs. HuURNA among examined cells.

Additional file $\mathbf{3}$ Statistically significant by t-test genes down-/upregulated vs. HuURNA among examined cells.

Additional file $\mathbf{4}$ Statistically significant genes by ANOVA down-/upregulated vs. HuURNA among examined cells. $p<0.01$ (shadow box), $p<0.05$ (open box).

\section{Competing interests}

The authors declare that they have no competing interests.

\section{Acknowledgements}

This research was supported by the Intramural Research Program of the National Institute of Diabetes and Digestive and Kidney Diseases and by grant from the Serbian Ministry of Education and Science [175053].

\section{Author details}

'Laboratory of Experimental Hematology, Institute for Medical Research, University of Belgrade, Belgrade 11129, Serbia. ${ }^{2}$ Tumor Vaccines and Biotechnology Branch, Division of Cellular and Gene Therapies, Center for Biologics Evaluation and Research, Food and Drug Administration, Bethesda, MD 20892, USA. ${ }^{3}$ Institute of Endocrinology, Diabetes and Diseases of Metabolism, School of medicine, University Clinical Center, Belgrade, Serbia. ${ }^{4}$ Molecular Medicine Branch, National Institute of Diabetes and Digestive and Kidney Diseases, National Institutes of Health, Bethesda, MD 20892, USA.

\section{Authors' contributions}

VPC carried out experimental work described in the paper, participated in designing the study, drafted the manuscript and performed the statistical analysis. BB carried out the molecular genetic studies. BBC drafted the manuscript and performed the statistical analysis. CTN participated in designing the study and helped to draft the manuscript. RKP conceived of the study, and participated in its design and helped to draft the manuscript. ANS participated in designing the study and helped to draft the manuscript. All authors read and approved the final manuscript.

Received: 12 March 2012 Accepted: 7 June 2012

Published: 7 June 2012

\section{References}

1. Welch JJ, Watts JA, Vakoc CR, Yao Y, Wang H, Hardison RC, Blobel GA, Chodosh LA, Weiss MJ: Global regulation of erythroid gene expression by transcription factor GATA-1. Blood 2004, 104:3136-3147.

2. Zhu J, Chin K, Aerbajinai W, Trainor C, Gao P, Rodgers GP: Recombinant erythroid Kruppel-like factor fused to GATA1 up-regulates delta- and gamma-globin expression in erythroid cells. Blood 2011, 117:3045-3052.

3. Miller IJ, Bieker JJ: A novel, erythroid cell-specific murine transcription factor that binds to the CACCC element and is related to the Krüppel family of nuclear proteins. Mol Cell Biol 1993, 13:2776-2786.

4. Tsang AP, Visvader JE, Turner CA, Fujiwara Y, Yu C, Weiss MJ, Crossley M, Orkin SH: FOG, a multitype zinc finger protein, acts as a cofactor for transcription factor GATA-1 in erythroid and megakaryocytic differentiation. Cell 1997, 90:109-119.

5. Tanimoto K, Liu Q, Grosveld F, Bungert J, Engel JD: Context dependent EKLF responsiveness defines the developmental specificity of the human 
-globin gene in erythroid cells of YAC transgenic mice. Genes Dev 2000, 14:2778-2794.

6. Asano H, Li XS, Stamatoyannopoulos G: FKLF-2: a novel Krüppellike transcriptional factor that activates globin and other erythroid lineage genes. Blood 2000, 95:3578-3584

7. Jiménez G, Griffiths SD, Ford AM, Greaves MF, Enver T: Activation of the $\beta$ globin locus control region precedes commitment to the erythroid lineage. Proc Natl Acad Sci USA 1992, 89:10618-10622.

8. Persons DA, Allay JA, Allay ER, Ashmun RA, Orlic D, Jane SM, Cunningham $J M$, Nienhuis AW: Enforced expression of the GATA-2 transcription factor blocks normal hematopoiesis. Blood 1999, 93:488-499.

9. Wen J, Huang S, Rogers H, Dickinson LA, Kohwi-Shigematsu T, Noguchi $C T$ : SATB1 family protein expressed during early erythroid differentiation modifies globin gene expression. Blood 2005, 105:3330-3339.

10. Casteel D, Suhasini M, Gudi T, Naima R, Pilz RB: Regulation of the erythroid transcription factor NF-E2 by cyclic adenosine monophosphatedependent protein kinase. Blood 1998, 91:3193-3201.

11. Gubin AN, Njoroge JM, Bouffard GG, Miller JL: Gene Expression in Proliferating Human Erythroid Cells. Genomics 1999, 59:168-177.

12. Fujishima N, Hirokawa M, Aiba N, Ichikawa Y, Fujishima M, Komatsuda A, Suzuki Y, Kawabata Y, Miura I, Sawada K: Gene expression profiling of human erythroid progenitors by micro-serial analysis of gene expression. Int J Hematol 2004, 80:239-245

13. Mitchell T, Plonczynski M, McCollum A, Hardy CL, Safaya S, Steinberg MH: Gene Expression Profiling during Erythroid Differentiation of K562 Cells. Blood Cells Mol Dis 2001, 27:309-319.

14. Merryweather-Clarke AT, Atzberger A, Soneji S, Gray N, Clark K, Waugh C, McGowan SJ, Taylor S, Nandi AK, Wood WG, Roberts DJ, Higgs DR, Buckle VJ, Robson KJ: Global gene expression analysis of human erythroid progenitors. Blood 2011, 117:e96-e108.

15. Steidl U, Kronenwett R, Rohr UP, Fenk R, Kliszewski S, Maercker C, Neubert P, Aivado M, Koch J, Modlich O, Bojar H, Gattermann N, Haas R: Gene expression profiling identifies significant differences between the molecular phenotypes of bone marrow-derived and circulating human CD34 ${ }^{+}$hematopoietic stem cells. Blood 2002, 99:2037-2044.

16. Arcasoy $\mathrm{MO}$, Jiang $\mathrm{X}$ : Co-operative signalling mechanisms required for erythroid precursor expansion in response to erythropoietin and stem cell factor. Br J Haematol 2005, 130:121-129.

17. Ratajczak J, Majka M, Kijowski J, Baj M, Pan ZK, Marquez LA, JanowskaWieczorek A, Ratajczak MZ: Biological significance of MAPK, AKT and JAKSTAT protein activation by various erythropoietic factors in normal human early erythroid cells. Br J Haematol 2001, 115:195-204.

18. Haseyama Y, Sawada K, Oda A, Koizumi K, Takano H, Tarumi T, Nishio M, Handa M, Ikeda Y, Koike T: Phosphatidylinositol 3-kinase is involved in the protection of primary cultured human erythroid precursor cells from apoptosis. Blood 1999, 94:1568-1577.

19. Narayan AD, Ersek A, Campbell TA, Colón DM, Pixley JS, Zanjani ED: The effect of hypoxia and stem cell source on haemoglobin switching. $\mathrm{Br} J$ Haematol 2005, 128:562-570

20. Cokic VP, Smith RD, Beleslin-Cokic BB, Njoroge JM, Miller JL, Gladwin MT, Schechter AN: Hydroxyurea induces fetal hemoglobin by the nitric oxidedependent activation of soluble guanylyl cyclase. J Clin Invest 2003, 111:231-239.

21. Brazma A, Hingamp P, Quackenbush J, Sherlock G, Spellman P, Stoeckert C, Aach J, Ansorge W, Ball CA, Causton HC, Gaasterland T, Glenisson P, Holstege FC, Kim IF, Markowitz V, Matese JC, Parkinson H, Robinson A, Sarkans U, Schulze-Kremer S, Stewart J, Taylor R, Vilo J, Vingron M: Minimum information about a microarray experiment (MIAME)-toward standards for microarray data. Nat Genet 2001, 29:365-371.

22. Risinger Jl, Maxwell GL, Chandramouli GV, Aprelikova O, Litzi T, Umar A, Berchuck A, Barrett JC: Microarray analysis reveals distinct gene expression profiles among different histologic types of endometrial cancer. Cancer Res 2003, 63:6-11.

23. Ikonomi P, Noguchi CT, Miller W, Kassahun H, Hardison R, Schechter AN: Levels of GATA-1/GATA-2 transcription factors modulate expression of embryonic and fetal hemoglobins. Gene 2000, 261:277-287.

24. Pang M, Ma L, Liu N, Ponnusamy M, Zhao TC, Yan H, Zhuang S: Histone deacetylase $1 / 2$ mediates proliferation of renal interstitial fibroblasts and expression of cell cycle proteins. J Cell Biochem 2011, 112:2138-2148.
25. Aho TL, Sandholm J, Peltola K, Ito Y, Koskinen PJ: Pim-1 kinase phosphorylates RUNX family transcription factors and enhances their activity. BMC Cell Biol 2006, 7:21.

26. Lacaud G, Gore L, Kennedy M, Kouskoff V, Kingsley P, Hogan C, Carlsson L, Speck N, Palis J, Keller G: Runx1 is essential for hematopoietic commitment at the hemangioblast stage of development in vitro. Blood 2002, 100:458-466.

27. Myklebust JH, Blomhoff HK, Rusten LS, Stokke T, Smeland EB: Activation of phosphatidylinositol 3-kinase is important for erythropoietin-induced erythropoiesis from $\mathrm{CD} 34^{+}$hematopoietic progenitor cells. Exp Hematol 2002, 30:990-1000

28. Sivertsen EA, Hystad ME, Gutzkow KB, Døsen G, Smeland EB, Blomhoff HK, Myklebust JH: PI3K/Akt-dependent Epo-induced signalling and target genes in human early erythroid progenitor cells. Br J Haematol 2006, 135:117-128.

29. Bouscary D, Pene F, Claessens YE, Muller O, Chrétien S, Fontenay-Roupie M, Gisselbrecht S, Mayeux P, Lacombe C: Critical role for PI 3-kinase in the control of erythropoietin-induced erythroid progenitor proliferation. Blood 2003, 101:3436-3443.

30. Sui X, Krantz SB, Zhao ZJ: Stem cell factor and erythropoietin inhibit apoptosis of human erythroid progenitor cells through different signalling pathways. Br I Haematol 2000, 110:63-70.

31. Migliaccio AR, Migliaccio G, Brice M, Constantoulakis P, Stamatoyannopoulos $G$, Papayannopoulou T: Influence of recombinant hematopoietins and of fetal bovine serum on the globin synthetic pattern of human BFUe. Blood 1990, 76:1150-1157.

32. Migliaccio G, Migliaccio AR, Adamson JW: In vitro differentiation of human granulocyte/macrophage and erythroid progenitors: comparative analysis of the influence of recombinant human erythropoietin, G-CSF, GM-CSF, and IL-3 in serum-supplemented and serum-deprived cultures. Blood 1988, 72:248-256.

33. Stoeckert CJ Jr, Green MB: Erythropoietin and hydroxyurea can act on early erythroid progenitors from adult human peripheral blood to modulate fetal globin mRNA levels. Exp Hematol 1994, 22:278-282.

34. Fujimori Y, Ogawa M, Clark SC, Dover GJ: Serum-free culture of enriched hematopoietic progenitors reflects physiologic levels of fetal hemoglobin biosynthesis. Blood 1990, 75:1718-1722

35. Schuringa JJ, Chung KY, Morrone G, Moore MA: Constitutive activation of STAT5A promotes human hematopoietic stem cell self-renewal and erythroid differentiation. J Exp Med 2004, 200:623-635.

\section{doi:10.1186/1479-5876-10-116}

Cite this article as: Cokic et al.: JAK-STAT and AKT pathway-coupled genes in erythroid progenitor cells through ontogeny. Journal of Translational Medicine 2012 10:116.

\section{Submit your next manuscript to BioMed Central and take full advantage of:}

- Convenient online submission

- Thorough peer review

- No space constraints or color figure charges

- Immediate publication on acceptance

- Inclusion in PubMed, CAS, Scopus and Google Scholar

- Research which is freely available for redistribution 